\title{
Pathogenesis of the inflammatory bowel disease in context of SARS-COV-2 infection
}

\author{
K. A. Dvornikova' ${ }^{1}$ - E. Yu. Bystrova' ${ }^{1}$ L. P. Churilov ${ }^{2} \cdot$ A. Lerner $^{3}$
}

Received: 17 February 2021 / Accepted: 13 July 2021 / Published online: 22 July 2021

(C) The Author(s), under exclusive licence to Springer Nature B.V. 2021

\begin{abstract}
To date, the latest research results suggest that the novel severe acute respiratory syndrome-related coronavirus 2 (SARS$\mathrm{CoV}-2$ ) can enter host cells directly via the gastrointestinal tract by binding to the enterocyte-expressed ACE2 receptor, or indirectly as a result of infection of type II alveolar epithelial cells. At the same time, entry of SARS-CoV-2 through the gastrointestinal tract initiates the activation of innate and adaptive immune responses, the formation of an excessive inflammatory reaction and critical increase in the expression of proinflammatory cytokines, which, subsequently, can presumably increase inflammation and induce intestinal damage in patients suffering from inflammatory bowel disease (IBD). The aims of the present review were to reveal and analyze possible molecular pathways and consequences of the induction of an innate and adaptive immune response during infection with SARS-CoV-2 in patients with IBD. A thorough literature search was carried out by using the keywords: IBD, SARS-CoV-2, COVID-19. Based on the screening, a number of intracellular and extracellular pathways were considered and discussed, which can impact the immune response during SARS-CoV-2 infection in IBD patients. Additionally, the possible consequences of the infection for such patients were estimated. We further hypothesize that any virus, including the new SARS-CoV-2, infecting intestinal tissues and/or entering the host's body through receptors located on intestinal enterocytes may be a trigger for the onset of IBD in individuals with a genetic predisposition and/or the risk of developing IBD associated with other factors.
\end{abstract}

Keywords Inflammatory bowel disease $\cdot$ Crohn's disease $\cdot$ Ulcerative colitis $\cdot$ Innate immunity $\cdot$ Adaptive immunity $\cdot$ Tolllike receptors $\cdot$ SARS-CoV-2 $\cdot$ COVID-19

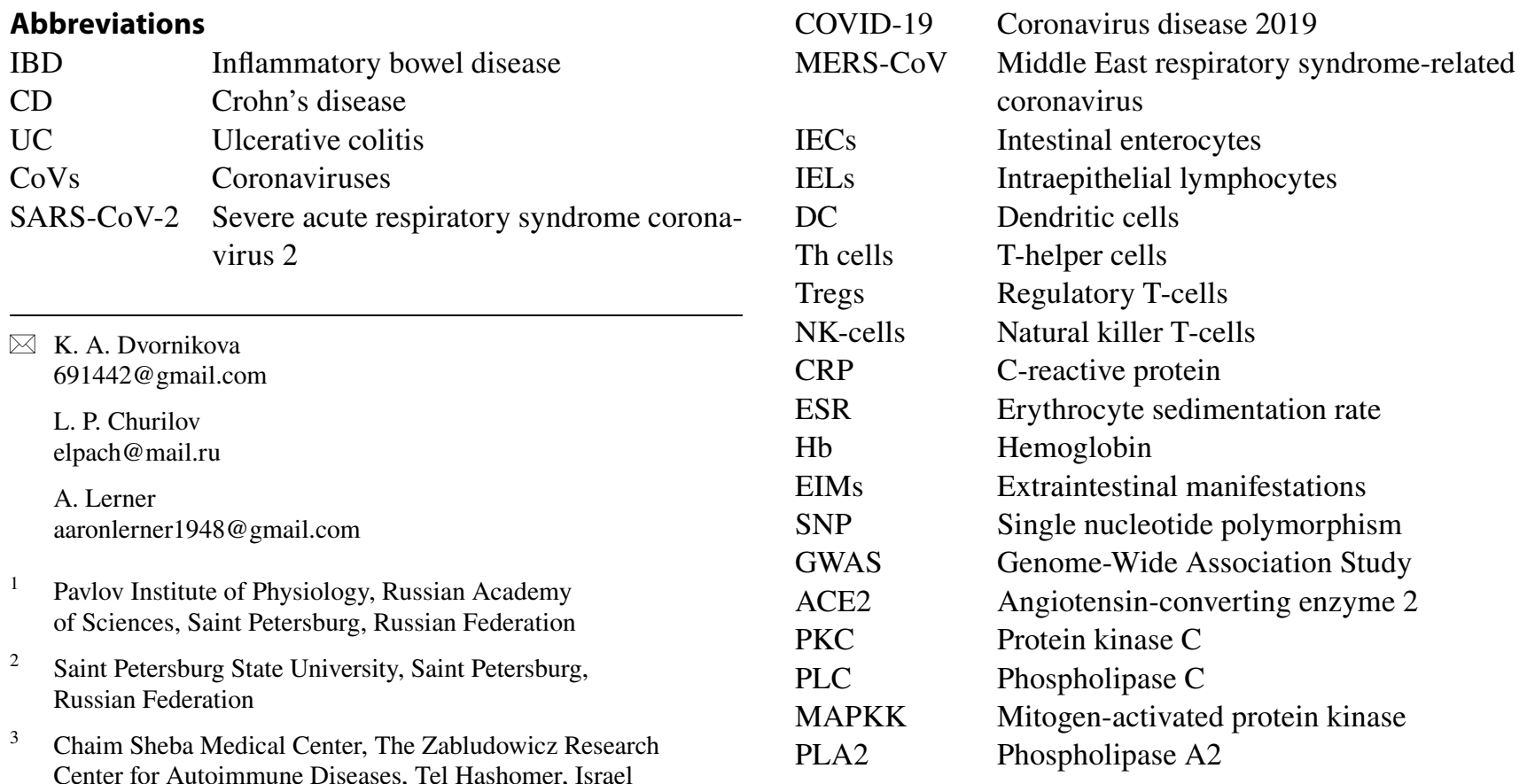




$\begin{array}{ll}\text { IL } & \text { Interleukin } \\ \text { TNF } & \text { Tumor necrosis factor } \\ \text { IFN } & \text { Interferon } \\ \text { TLRs } & \text { Toll-like receptors } \\ \text { TRPV } & \text { Transient Receptor Potential Vanilloid } \\ \text { NLR } & \text { NOD-like receptor } \\ \text { RLR } & \text { RIG-I-like receptors, Retinoic acid-induci- } \\ & \text { ble gene-I-like receptors } \\ \text { HLA } & \text { Human leukocyte antigen gene }\end{array}$

\section{Introduction}

The important facet of SARS-CoV-2 infection is related to the alleged ability of the virus to enter host organism through the gastrointestinal tract directly by binding to the ACE2 receptor widely expressed on intestinal enterocytes (IECs). The entry of SARS-CoV-2 through the gastrointestinal tract initiates the activation of innate and adaptive immune responses, the formation of an excessive inflammatory reaction and critical increase in the expression of proinflammatory cytokines, which, subsequently, can presumably increase inflammation and intestinal damage in patients with IBD. To date, the mechanisms of damage of the organs of the gastrointestinal tract associated with COVID-19 are not exactly known and require additional studies. It also remains unclear whether SARS-CoV-2 intestinal lesions are the result of a primary, secondary, or combined intestinal infection.

The present article analyzes the possible molecular pathways for the initiation of an innate and adaptive immune response when patients with IBD are infected with SARS$\mathrm{CoV}-2$ via a putative alternative pathway - the gastrointestinal tract with viral attachment to the epithelial ACE2 receptors. Additionally, the estimated consequences of the infection, for such patients, are described, and potential drug interactions for IBD with SARS-CoV-2 are offered.

A thorough literature search was carried out by using the keywords: IBD, SARS-CoV-2, COVID-19, by screening PubMed, MEDLINE and Science Direct databases, spanning the years 2002-2021.

\section{General description of IBD}

Inflammatory Bowel Disease is a group of chronic diseases of the gastrointestinal tract, the etiology of which currently remains completely unclear. Studies on the geoepidemiology of IBD disclosed that it is characterized by a significant West-East shift. The incidence in Western countries has stabilized, hence surged in various developing industrial countries [1]. At the same time, the prevalence of diseases increases constantly throughout the world. Its onset usually occurs during adolescence, and subsequently leads to the development of recurrent morbid chronic disease.

IBD includes two main types of disorders: UC and CD. Those are different entities that differ in the target area, pathophysiology, symptoms, course of the disease, treatment and potential complications.

UC is characterized by a unique involvement of the colon, the inflammation is superficial, resulting in erosions, ulcers, diarrhea, blood and mucus in the stool. UC is characterized by increased levels of eicosanoids, which play a pathophysiological role in inflammation. The usual clinical course of $\mathrm{UC}$ is represented by periods of exacerbation and remission. In the exacerbation phase, an increase in C-reactive protein (CRP), erythrocyte sedimentation rate (ESR), an increase in the production of major pro-inflammatory cytokines [interleukin-1 (IL-1), interleukin-6 (IL-6), interleukin-8 (IL-8) and tumor necrosis factor- $\alpha(\mathrm{TNF}-\alpha)$ ], as well as a decrease in hemoglobin $(\mathrm{Hb})$ can be observed. Therapy includes oral or topical administration of 5-aminosalicylic acid (5-ASA) and corticosteroids, but such treatment is available only for mild to moderate recurrent disease. When highly active, immunosuppressive drugs and/or biological therapy can be offered. Fecal microbiota transplantation is currently being considered as a promising new therapy that has proven to be effective for inducing remission in UC [2].

Crohn's disease is characterized by intestinal lesions in any segment along the gastrointestinal tract (from the mouth to the anus) and includes chronic recurrent transmural inflammation that can lead to chronic abdominal pain, diarrhea, obstruction, or perianal lesions [3]. CD develops as a result of an excessive response of Th1 (T-helper 1) and Th17 (T-helper 17) cells to proinflammatory cytokines such as interleukins IL-12, IL-18 and IL-23, which are produced by antigen-presenting cells and macrophages [4]. In 21-47\% of patients, CD can be accompanied by extraintestinal manifestations (EIMs). EIMs can affect any organ system, including the musculoskeletal, dermatologic, renal, hepato-pancreato-biliary, pulmonary and visual systems [5]. For example, progressive ankylosing spondylitis (AS) occurs in $25-75 \%$ of CD patients [6]. In $50 \%$ of affected patients, intestinal complications such as strictures or fistulas may develop within 10 years after the diagnosis of CD [7]. There is a constant need for rational and optimized anti-inflammatory therapy to prevent the progression and subsequent complications of the disease. Previously, treatment was aimed at alleviating only clinical symptoms, but recently, new effective mode of therapies was developed aiming to reach clinical remission (including those free of steroids) and transmural healing of the intestinal mucosa [8]. The development of biological drugs targeting specific inflammatory mediators has been a breakthrough in the treatment of $\mathrm{CD}$. Thus, antibodies against TNF (anti-TNF- $\alpha$ therapy) became the first class of substances approved for the treatment of $\mathrm{CD}$, and subsequently 
antibodies against integrin $\alpha 4 \beta 7$ (vedolizumab), IL-12 and IL-23 were approved [9].

Exploring the mechanisms and pathophysiology of IBD is the basis for understanding the origin of $\mathrm{CD}$ and $\mathrm{UC}$, in order to develop new strategies for effective therapy. At present, it is known that the inflammation in IBD can be mediated by impaired intestinal barrier function, defects in the regulation of innate and adaptive immune responses, and dysbiotic changes in the intestinal microbiome [3,10-14]. Other factors capable of inducing IBD are polygenetic and various environmental factors [15-17].

\section{Viral infections and IBD}

Due to impaired immune activation and excessive cytokine response, viral infections can complicate the course of $\mathrm{CD}$ and UC [18].

It should be noted that in the ileum and colon, there is an extensive expression of the angiotensin-converting enzyme 2 (ACE2) molecule, to which the new SARS-CoV-2 coronavirus binds, as well as an increased expression of the Transmembrane protease, serine 2 (TMPRSS2), which is necessary to activate the viral S-protein peplomer. This can lead to the penetration of the virus through the cells of the intestinal epithelium and, as a consequence, cause inflammation and/or aggravate the course of diseases of the enteric tract [19].

It is important to note that in case of patients with active $\mathrm{UC}$, an increased level of ACE2 expression is observed, which suggests the possibility of a more severe course of infection and/or aggravation of the course of UC [20].

According to the available information regarding the effect of viral infections on the course of IBD, it can be assumed that any viruses (including the new SARS-CoV-2) affecting intestinal tissue and/or entering the host's body through receptors located on IECs of the intestine may be a trigger for the onset of IBD in individuals with a genetic predisposition and/ or having the risks of developing IBD. Based on the above, a comprehensive analysis of the available data on the molecular mechanisms of interaction and possible intersection of signaling pathways during SARS-CoV-2 infection in patients with IBD, was conducted. Highlighted are the aspects of development and aggravation of the course of IBD under the influence of components of innate and adaptive immunity expressed in response for SARS-CoV-2 infection. A detailed analysis of the impact of the novel coronavirus infection on the course of IBD is presented in the following sections.

\section{Coronavirus infection}

Coronaviruses (CoVs) are RNA viruses of the Coronaviridae family that infect mammals (including humans), birds, and amphibians [21]. To date, 46 types of CoVs are known, of which 7 can infect humans, namely: Human coronavirus 229E (HCoV-229E), Human coronavirus NL63 (HCoVNL63), Human coronavirus OC43 (HCoV-OC43), Human coronavirus HKU1 (HCoV -HKU1), Middle East respiratory syndrome-related coronavirus (MERS-CoV), Severe acute respiratory syndrome coronavirus (SARS-CoV or SARS-CoV-1) and a new species Severe acute respiratory syndrome coronavirus 2 (SARS-CoV-2) [22]. The structure of different types of CoVs is similar: enveloped, singlestranded, with a genome of 26-32 kb, with RNA of positive polarity, and a phosphorylated nucleocapsid (N-protein). On the outer side of the lipid membrane of the $\mathrm{CoV}$ virion, there are glycoprotein spikes (S-protein)—peplomeres resembling a crown which binds to the surface structures of the cytoplasmic membrane of the host cell. Moreover, the binding of the S-protein to the receptor in the host organism is strictly specific for each $\mathrm{CoV}$ species. In particular, the MERS-CoV species binds to the dipeptidyl peptidase 4 (DPP4) receptor, which is an important factor in signal transduction and activation of innate and adaptive immunity [23]. Another type-SARS-CoV-1 binds to the receptor of angiotensinconverting enzyme 2 (ACE2) - a membrane protein on macrophages, epithelial cells, microglia, neurons, as well as to the CD147 receptor (Basigin); extracellular matrix metalloproteinase inducer (EMMPRIN) on erythrocytes [24]. In addition to S-protein, the structure of the lipid membrane includes structural E-protein and M-protein, which can participate in the formation of an inflammatory response and in the suppression of signal transduction pathways of the innate immune system [25]. CoVs are spread from person to person by airborne droplets. Typically, in humans, CoVs affect the upper and/or lower respiratory tract with mild to moderate respiratory symptoms such as fever, cough, sore throat, headache. In general, the course of the infection is mild or asymptomatic. However, CoVs such as SARS and MERS can cause severe symptoms, complications and death [26]. A new species SARS-CoV-2 according to the available information is also capable of causing severe complications, including gastrointestinal ones, as discussed in detail below.

\section{SARS-CoV-2: a new coronavirus}

SARS-CoV-2 is a new $30 \mathrm{~kb}$ single-stranded polycistronic RNA virus (+ ssRNA) of the genus Betacoronavirus B, which has genomic homology with SARS-CoV-1 and causes an infectious disease-COVID-19, the spread of which led to the announcement of a pandemic in 2019 [27]. The structure of SARS-CoV-2 is typical for different types of CoVs: first, 4 structural proteins $\mathrm{S}, \mathrm{E}, \mathrm{M}, \mathrm{N}$ (with the exception of the hemagglutinin esterase (HE) protein) are necessary for the assembly and infection of $\mathrm{CoV}$, of which S-protein (ORF2) is key in binding to the host receptor and fusion with the cell membrane (Fig. 1). It is noted that S-proteins 
of SARS-CoV-2 and SARS-CoV-1 have a homology of the amino acid sequence of about $77 \%$, which may indicate a possible cross-reaction [28]. E-protein (ORF4) is required for the assembly and release of $\mathrm{CoV}$ virions. M-protein (ORF5) can change the membrane conformation and bind to the nucleocapsid (N-protein (ORF9)) containing $\mathrm{N}$-terminal RNA-binding and C-terminal domains, the interaction of which with the viral RNA leads to the formation of ribonucleoprotein. It is reported that $\mathrm{N}$-protein is an important component for the morphogenesis phase of SARS-CoV-2 life cycle, as well as an RNA interference repressor and an IFN- $\beta$ antagonist [29]. Notably, S, E, M, and N proteins of SARS-CoV-2 have a higher gene expression efficiency than that of other SARS and MERS species [30].

The structure of SARS-CoV-2 also includes 11 open reading frames (the largest ORFs $1 \mathrm{a}$ and $1 \mathrm{~b}$ ) expressing two polypeptides pp1a and pp1ab, which are then cleaved into 16 non-structural proteins (nsp1-16) that play a role in the processes of replication and inhibition of the host immune response (Fig. 1) [31]. Additional proteins were found in SARS-CoV-2: ORF3a, an ion channel protein that promotes TRAF3-dependent ubiquitination of ASC; ORF6 - an auxiliary protein associated with the activity of RNA polymerase; ORF7a-a protein encoding type I transmembrane protein; ORF7b-an accessory protein and structural component of SARS-CoV-2 virion; as well as proteins, the functions of which are not yet precisely known: ORF3b, ORF8, ORF10 (Fig. 1). It is assumed that those proteins can play an important role in pathogenesis and, in the long-term, may be used for the development of new therapeutic strategies for the treatment of COVID-19 [29].

During the present pandemic, Genome-Wide Association Study (GWAS) studies of the SARS-CoV-2 genome are being conducted, aimed at finding possible Single nucleotide polymorphism (SNP) that may affect the severity and spread of COVID-19. The identification of SNP in the coding and non-coding regions of the SARS-CoV-2 genome is necessary to study the evolution of the genome, as well as to identify the genetic variations of the virus for further vaccine development. SNP detection allows for tracking of conserved and variable genes. $115 \mathrm{SNP}$ were identified in the SARS-CoV-2 genome, of which 52 are synonymous, 46 are nonsynonymous SNP, 2 insertions, 1 deletion, and 14 SNP in the $3^{\prime}$-UTR and 5'-UTR regions. The overwhelming majority of the detected SNP (for example, the most frequent SNP variant, $8782 C>T$ ) are located in the Orflab gene, an important factor in the processes of viral replication and transcription. The results of the analysis may indicate the conservatism of 52 SNP genes and their significance for the functioning of SARS-CoV-2 [32]. However, to date, there is insufficient information to accurately establish the influence of SNP in the SARS-CoV-2 genes on the course of COVID-19,

A

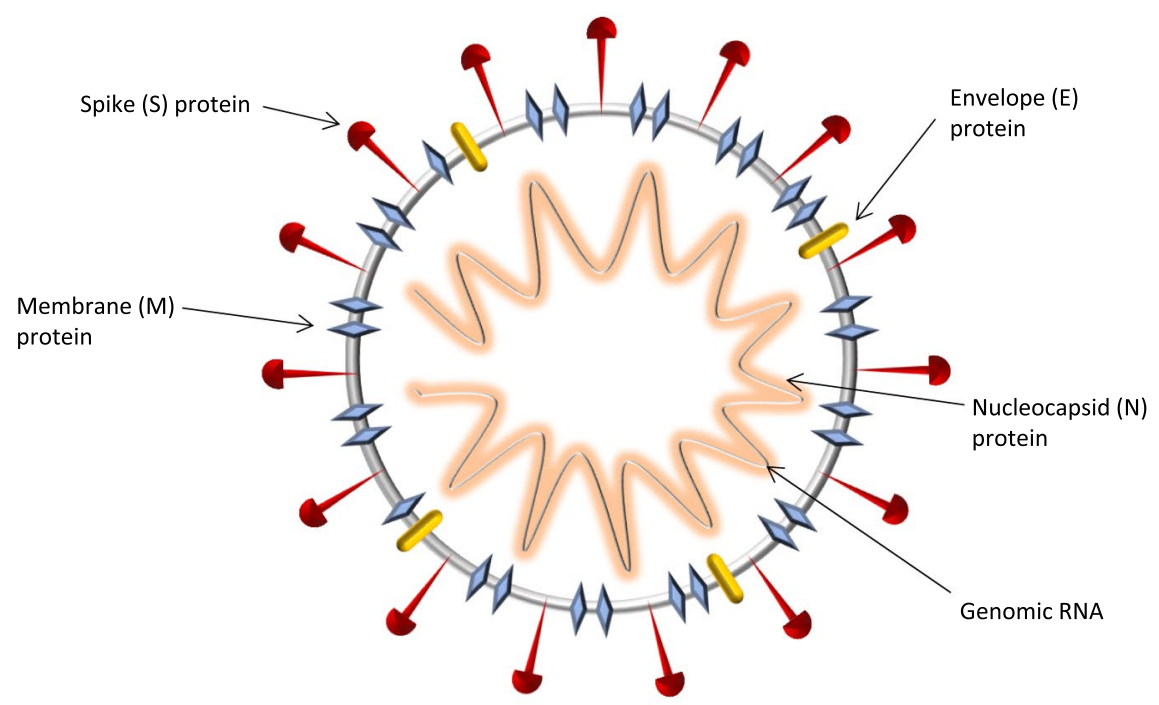

B

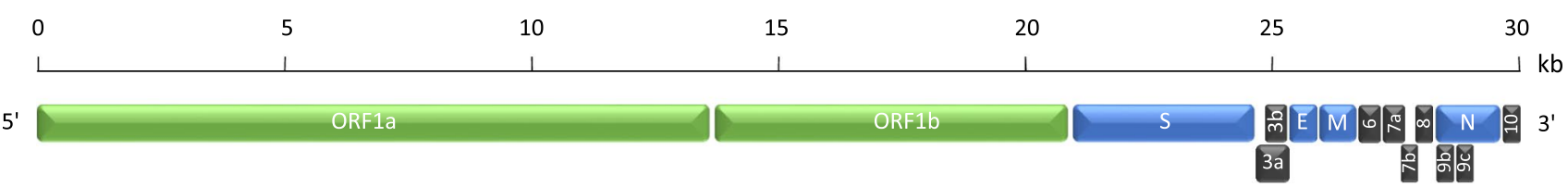

Fig. 1 Virion structure (a) and SARS-CoV-2 genome structure (b) (original scheme) 
the aggravation of other diseases and/or a possible role in the signaling pathways of innate and adaptive immunity. Further research is highly required.

SARS-CoV-2, like most CoVs, is transmitted from person to person by airborne droplets and through contaminated surfaces. It is known that ACE2 has an affinity for S-glycoprotein of SARS-CoV-2 and is the entry point into the host cell [20]. ACE2 is expressed in most tissues: on the membranes of type II pneumocytes, enterocytes of the small intestine, endothelial cells of arteries and veins, smooth muscle cells, in cells of the cortex and brainstem, hypothalamus, etc. Thus, the variety of sites of localization of the ACE2 receptor can allow the penetration of SARS-CoV-2 into the human body in different ways, which increases the chance of infection. However, there is no evidence that the level of ACE2 expression can be related to the penetration ability of SARS-CoV-2.

SARS-CoV-2 in humans affects the upper and/or lower respiratory tract with mild to severe symptoms ranging from fever, cough, sore throat and anosmia to pneumonia and acute respiratory distress syndrome (ARDS) [26]. The course of the infection is also possible in an asymptomatic form. There is evidence of additional symptoms during infection with SARS-CoV-2, depending on the place of attachment of S-protein of the virus to ACE2, which is expressed on different types of cells-on pneumocytes, enterocytes, hepatocytes, etc. Moreover, according to results of recent studies, many patients with COVID-19 may experience kidney, heart, liver, brain, and gastrointestinal tract organs damage [19, 29]. At the same time, it has been reported that SARS-CoV-2 is able to act as a trigger factor for the development of rapid autoimmune and/or autoinflammatory dysregulation, leading to severe interstitial pneumonia in individuals with a genetic predisposition [33]. An immunohistochemical study has demonstrated diffuse infiltration of lungs, along with a different extent of focal infiltration of kidney, liver, intestine, adrenal glands, pancreas and pericardium by lymphocytes. According to the results of the analysis of the infiltrates, it was found that $\mathrm{CD}^{+}{ }^{+} \mathrm{T}$-cells and $\mathrm{CD} 8^{+} \mathrm{T}$-cells predominate in the infiltrate of the lungs, adrenal glands, liver, intestine and other organs, and there is also partial tissue damage, which hints to autoimmune process [34]. Interestingly, information is accummulated that SARS-CoV-2 can induce autoimmune reactions through molecular mimicry [35]. In particular, the discovery of 233 immunoreactive linear epitopes in SARS$\mathrm{CoV}-2$, consisting of peptide sequences that are also present in human proteins, has been reported [36]. The study noted that the sharing of peptide sequences between immunoreactive epitopes from SARS-CoV-2 and human proteins can cause cross-reactivity, and as a result, these cross-reactive reactions can lead to the development of various autoimmune pathologies. Another study identified chaperones [37] (mainly heat shock proteins) that are suspected of being involved in molecular mimicry after infection with SARS$\mathrm{CoV}-2$. These and other research results $[38,39]$ can provide better understanding of the possible mechanisms underlying the formation of cross-reactivity of SARS-CoV-2 peptides with host autoantigens.

A number of studies reports the effect of SARS-CoV-2 on the development of autoimmune diseases in genetically predisposed patients in the context of the Human leukocyte antigen (HLA) gene [40]. It was previously noted that HLA and its polymorphism are associated with the development of various autoimmune diseases [41]. Recent research is focusing on finding HLA genotypes associated with the severity of COVID-19 or susceptibility to SARS-CoV-2 [42, 43]. Patients with the HLA-A genotype can efficiently generate T-cell mediated antiviral responses to SARS-CoV-2. Other alleles-HLA-B, HLA-C, HLA-DPB1, HLA-DRB1, and HLA-DQB1 did not show such results. Further research in this area will help to improve support/treatment for patients at a genetic risk.

Following is a summary of pathophysiological pathways, symptoms, short and long-term complications associated with SARS-CoV-2 infected human enteric tract.

\section{SARS-COV-2 and the digestive system}

The ACE2 receptor is expressed at a high level in enterocytes of the small intestine, colon and ileum, as well as in a smaller amount in the epithelial cells of the esophagus, stomach, duodenum, and rectum [44]. This allows SARSCoV-2 to enter the gastrointestinal tract, and the binding of the virus to the ACE2 receptor in the gastrointestinal tract. The resulting subsequent replication can pose a potential threat to patients with diseases of the digestive system, in particular with IBD [19].

Since the beginning of the Covid-19 Pandemic numerous publications have reported on the detection of viral RNA in rectal swabs and feces of patients with COVID-19, which may serve as confirmation of an extra-pulmonary, additional fecal-oral route of transmission of SARS-CoV-2 [45, 46]. It is important to note, that patients having a negative analysis for the presence of SARS-CoV-2 RNA obtained by a swab from the nasopharynx and oropharynx may have a positive stool sample, which is an additional possibility of fecal-oral transmission of the virus even after SARSCoV-2 is eradicated from the respiratory paths [47]. However, further research is required to confirm this hypothesis. The main gastrointestinal symptoms of COVID-19 patients include nausea, diarrhea, vomiting, and abdominal pain, but these symptoms were found to be less common compared to MERS-CoV. This may indicate differences in the viral tropism of SARS-CoV-2 and MERS-CoV. The expression of 
ACE2 on different cells of the digestive system can presumably be the cause of certain gastrointestinal symptoms. As a result, the expression of ACE2 in absorbing enterocytes of the ileum and colon may explain diarrhea in patients with COVID-19, and the expression of ACE2 in multilayered epithelial cells of the esophagus can be a reason for esophagitis caused by COVID-19 [48, 49].

Damage of the digestive system organs due to SARS$\mathrm{CoV}-2$ infection has been recently reported. In particular, after the dissection of the intestine of a patient with COVID19 , the presence of segmental dilatation and stenosis of the small intestine, as well as infiltration of the lamina propria, duodenum and rectum with plasma cells and lymphocytes, was noted [50]. More so, SARS-CoV-2 infection was detected as the cause of hemorrhagic colitis in a patient with COVID-19 [51]. The RNA of the virus was detected in a stool sample, and the results of examination of the colon, sigmoid and rectum confirmed damage and infection in the colon. It has been shown that ACE2 is expressed at a high level in cholangiocytes and hepatocytes, suggesting a possible role for ACE2 in the pathogenesis of liver damage in COVID-19 [52]. When infected with COVID-19, the condition of patients with concomitant liver disease could potentially worsen due to the increased expression of ACE2 caused by hypoxia during the cytokine storm. However, the exact mechanism of liver damage is unclear. Several pathogenic mechanisms were suggested for the hepatic deterioration: viral cytopathic effects, cytokine storm, hypoxia, and hepatotoxic drugs [53]. In general, the mechanisms of damage to the gastrointestinal tract organs associated with COVID-19 are not exactly known and require further study. It also remains unclear whether SARS-CoV-2 intestinal lesions are the result of a primary, secondary, or combined intestinal infection.

Of note is the fact that SARS-CoV-2 in the intestine can prevent tryptophan from entering via the AT1/ACE2 transport pathway [54]. Tryptophan regulates the secretion of antimicrobial peptides that affect the composition of the intestinal microbiota, and along with its metabolite nicotinamide, is a key regulator of the predisposition to inflammation. As a result, disruption of tryptophan supply results in decreased levels of antimicrobial peptides and altered gut microbiota, causing inflammation. However, this molecular mechanism has only been established in mice. Nevertheless, there is evidence supporting dysbiosis of the gut microbiota in some patients with COVID-19, in particular, in the form of a decrease in the number of Lactobacillus and Bifidobacterium [55]. This mechanism could hypothetically overlap and/or influence the pathophysiology of IBD, as inflammation in IBD also includes, among other things, dysbiosis of the gut microbiota [11].

Thus, the pathogenesis of SARS-CoV-2 has not yet been fully understood, in particular, on the viral infection in patients with IBD. Currently, various options of SARSCoV-2 entry into the body are being considered, including the primary respiratory one and the alternative way through the oral-enteric tract [29]. At the same time, it cannot be unambiguously asserted whether entering of SARS-CoV-2 into the intestine occurs directly by attachment to ACE2, which is expressed on enterocytes, or indirectly as a result of infection of type II alveolar epithelial cells. Further research is required to confirm or refute this concept. Based on the available information, an analysis of SARS-CoV-2 infection in patients with IBD through the gastrointestinal tract with attachment of the virus to the local ACE2, was carried out. Possible molecular pathways and the alleged consequences of SARS-CoV-2 infection were demonstrated. A detailed analysis is provided below.

\section{Possible molecular mechanisms of the immune response to SARS-COV-2 infection in patients with IBD}

It has been established that SARS-CoV-2 has two intracellular molecular pathways for the transfer of genetic material into the host cell-endosomal and membrane (cytoplasmic). Each of them leads to the activation of innate and adaptive immunity, to the formation of an excessive inflammatory response and, in some cases, to a critical increase in the expression of pro-inflammatory cytokines (Fig. 2) [56]. In addition, extracellular adaptive and innate immune responses are initiated as a result of SARS$\mathrm{CoV}-2$ entering into the human body. The consequences are induced expression of proinflammatory cytokines, chemokines, and acute inflammation.

\section{Intracellular adaptive and innate immune responses}

As a result of SARS-CoV-2 entering the human intestine, the virus collides with the intestinal barrier: IECs, immune cells of innate and adaptive immunity (macrophages, neutrophils, dendritic cells, T cells), intraepithelial lymphocytes (IELs) and mucous membranes [57]. Taking together, the occurrence of a problem in one of the components of the intestinal barrier can lead to disruption of its functions, in particular, increased permeability, which, in turn, is associated with the development of IBD. It was previously noted that impairments in the secretory activity of Paneth cells, specialized IECs present at the base of intestinal crypts in the small intestine, may lead to the development of CD [58]. It can also be an important factor in facilitating the passage of SARS-CoV-2 through the intestine. 


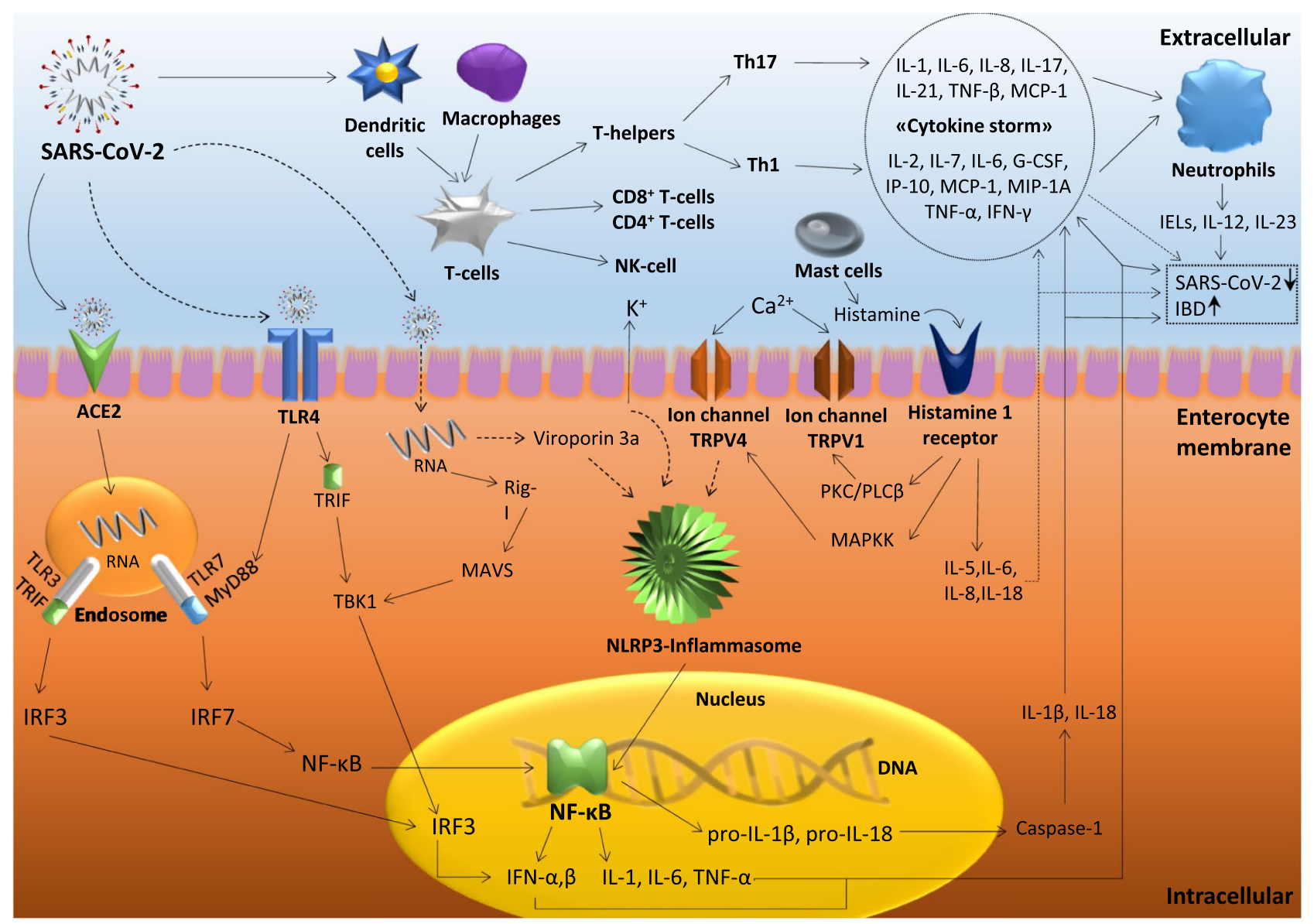

Fig. 2 Molecular pathways and implications of innate and adaptive immune responses following infection with SARS-CoV-2 in patients with IBD. The dotted lines indicate the suggested paths (original scheme)

\section{Endosomal pathway}

Following the attachment of SARS-CoV-2 S-glycoprotein to the ACE2 receptor expressed on IECs in the human intestine, the virus is transported to the endosome where it releases its RNA (Fig. 2). Endosomal receptors TLR3 and TLR7 recognize viral RNA and transmit a signal to downstream mediators through two different pathways: by activation of the TRIF-dependent pathway with the induction of IRF3 factor, which induces the production of IFN- $\alpha$, $\beta$ (TLR3 pathway) and through activation of the MyD88dependent pathway followed by inducing of transcription factor NF- $\mathrm{KB}$ to produce proinflammatory cytokines (TLR7 pathway). Importantly, TLR3 expression in IECs is significantly suppressed in patients with active IBD. This can lead to decreased recognition of viral RNA by the receptor and to the development and/or worsening of COVID-19. Additionally, the combined genetic variations of TLR3 and TLR7 can significantly affect the severity of UC in patients with IBD upon infection with the virus [59]. Intriguingly, TLR3 and TLR7 are able to stimulate the secretion of IFN- $\beta$ by plasmacytoid dendritic cells (pDCs), thereby contributing to the development of an additional protective immune response.

\section{Membrane (cytoplasmic) pathway}

The membrane receptor TLR4 has a strong affinity for SARS-CoV-2 S-glycoprotein and can participate in the recognition of molecular patterns of the virus [60,61]. After recognition of S-glycoprotein by TLR4 receptor, signaling occurs via two different pathways: through the TRIFdependent pathway with the activation of TBK1 kinase, phosphorylation of IRF3 factor, subsequent production of IFN- $\alpha, \beta$ and expression of the pro-inflammatory cytokines IL-6 and TNF- $\alpha$, or through MyD88-dependent pathway similar to TLR7 (Fig. 2). At the same time, a negative role of the TLR4 signaling pathway in IBD was previously described. In particular, the involvement of TLR4 in the development of IBD and the destructive effect on intestinal epithelial tissues and ulceration in patients with UC has been reported, due to the release of pro-inflammatory 
cytokines that aggravate intestinal inflammation [13]. This can be an important aggravation stimulus in the course of IBD and one of the reasons for the immunopathological manifestation of COVID-19 in patients with IBD. Intestinal inflammation associated with the TLR4 signaling pathway, can presumably provoke the activation of opportunistic and pathogenic intestinal microbiota, as well as change the species diversity of intestinal bacteria, which together can lead to a strong reaction, increased expression of cytokines and pronounced pathological consequences in patients with IBD.

A number of experimental evidences indicating the ability of histamine to modulate the inflammatory responses of various types of cells to infectious agents, in particular by regulating the expression of TLRs are available. This mediator is involved in the regulation of both specific and nonspecific immune responses, while many immune cells, including various subpopulations of T-lymphocytes, B-lymphocytes, Natural killer T-cells (NK-cells), macrophages, etc., express histamine receptors. Important immunomodulatory effects of histamine are primarily associated with the ability to regulate cytokine production, both negatively and positively. Data available to date indicate that histamine is able to inhibit the production of IL-1, IL- 2 , IFN- $\gamma$, TNF- $\alpha$ by Th-helpers, and stimulate the release of IL-5, IL-6, IL-8, IL-18 by Th2. The histamine-induced enhancement of the cell response to the penetration of pathogens, accompanied by the production of pro-inflammatory and anti-inflammatory agents, in some cases, is associated with an increase in the expression of TLRs and the development of an inflammatory response. Interestingly, the currently available data indicate that histamine may act as a sensitizing agent that modulates nociceptive signals, in particular, indirectly through Transient Receptor Potential Vanilloid (TRPV1) receptor channel [62]. At the same time, sensitization of TRPV1 with histamine via the H1R-receptor pathway may cause the development of visceral hypersensitivity and corresponding symptoms in individuals with IBD. Based on the information available in the literature, it can also be assumed that TLRs are able to modulate the TRPV1 expression pattern, both directly and through signaling pathways associated with histamine and its receptors, inducing corresponding physiological responses. Thus, one cannot exclude a certain pathological role of histamine as a component of signaling pathways associated with the formation of an immune response upon infection with SARS-CoV-2. Indeed, the entry of the virus into the gastrointestinal tract can stimulate the secretion of histamine by mast cells, which, in turn, is capable of activating the cellular and humoral immune response, including regulating the expression of TLRs and the production of cytokines. At the same time, subsequent sensitization of TRPV1 with histamine via the H1R receptor pathway is also possible, which ultimately will lead to increased inflammation and worsening of the IBD clinical state.

SARS-CoV-2 can induce the assembly and activation of the NLRP3-inflammasome, a member of the NOD-like receptor (NLR) family, which is formed in response to the invasion of various pathogens and plays an important role in the inflammatory response as one of the main components of innate immunity [63]. The introduction of SARS-CoV-2 is accompanied by the recognition of RNA and viral proteins, which triggers a cascade of regulatory reactions leading to the assembly of the NLRP3-inflammasome formed by the proteins NACHT, LRR, NLRP3, ASC, procaspase 1 and subsequent activation of this complex [64]. NLRP3-inflammasome is formed in the cytosol and controls the secretion of the pro-inflammatory cytokines IL- $1 \beta$ and IL-18 and other damage-associated molecular patterns (DAMP). At the same time, activation of NF- $\mathrm{BB}$ allows to quickly stimulate the expression of pro-IL-1 $\beta$ and pro-IL-18, which are then cleaved by Caspase- 1 into mature IL- $1 \beta$ and IL- 18 in the inflammasome (Fig. 2). Moreover, the leakage of $\mathrm{K}^{+}$ions and the influx of $\mathrm{Ca}^{2+}$ ions through ion channels formed by the structural and non-structural proteins of SARS-CoV-2 is another factor in the activation of the NLRP3-inflammasome [64]. Intracellular $\mathrm{K}^{+}$depletion has been shown to shift ionic equilibrium to the acidic zone, which is sufficient for the onset of inflammation and activation of the NLRP3 inflammasome (Fig. 2). Presumably, histamine-induced intracellular calcium signals from the TRPV4 receptor may also activate the NLRP3-inflammasome (Fig. 2). It is known that histamine can enhance the $\mathrm{Ca}^{2+}$ responses induced by a TRPV4 agonist ( $4 \alpha \mathrm{PDD}$ ) through the Protein kinase $\mathrm{C}$ (PKC), Phospholipase C (PLC $\beta$ ), Mitogen-activated protein kinase (MAPKK) and Phospholipase A2 (PLA2) signaling pathways, as well as lead to an increase in TRPV4 expression on the cell membrane in a MAPKK-dependent manner, thereby providing the development of visceral hypersensitivity symptoms and worsening the course of the disease [65].

The expression of SARS-CoV-2 Viroporin 3a protein can stimulate the secretion of IL-1 $\beta$ (Fig. 2) [66]. It is important to mention that this viral protein is found in the SARS$\mathrm{CoV}-2$ genome. This suggests that the virus can directly activate the NLRP3-inflammasome. In turn, activation of NLRP3-inflammasome by recognizing SARS-CoV-2 RNA in patients with IBD can increase inflammation and aggravate colon lesions, but on the other hand, it can also prevent damage to non-inflamed mucosa under stable conditions in IBD [67]. In fact, the activation of NLRP3-inflammasome has a positive effect on host defense during infections and metabolic processes, however, excessive production of IL-1 $\beta$ and IL-18 can lead to severe inflammation, causing metabolic and auto-inflammatory complications in patients with IBD: penetration of neutrophils into tissues, distortion of Th17 differentiation, which will contribute to extensive 
tissue damage. However, most of the mechanisms and precise role of the NLRP3 inflammasome in IBD are obscure. Further research is highly required.

It is hypothesized that SARS-CoV-2 can enter the IECs of the human intestine through pinocytosis (Fig. 2). As a result, the RNA of the virus is recognized by key RIG-Ilike receptors (RLR), in particular, Rig-I (DDX58), which specifically recognizes viral RNA with subsequent interaction with the adapter protein MAVS and activation of TBK1 kinase, inducing the production of IRF3 and NF- $\mathrm{KB}$, which ultimately causes the production of IFN- $\alpha, \beta$ and the expression of proinflammatory cytokines [22]. Additionally, RIG-I/ TLR3/NLRP3-dependent activation of IRF3, IRF7 and $\mathrm{NF}-\kappa \mathrm{B}$ has been reported, which also leads to the production of IFN- $\alpha, \beta$, and pro-inflammatory cytokines [68]. Further, it was found that selective suppression of Rig-I in IECs of patients with IBD is accompanied by changes in the innate immune response of the mucous membrane (especially in $\mathrm{CD}$ ) and disruption of the intestinal microbiome composition, which may aggravate the course of IBD. However, to date, there are no data supporting the significance of inhibited Rig-I in IECs for the pathogenesis of CD, and there are no studies of Rig-I suppression in the context of SARSCoV-2 infection in IBD patients and studying the effect of the virus on the development and progression of IBD. It can be assumed that the lack of activity of the RIG-I protein and the entry of SARS-CoV-2 into IECs of the intestine by pinocytosis will contribute to the development and progression of COVID-19 in IBD affected patients.

\section{Extracellular adaptive and innate immune responses}

Macrophages, along with intestinal dendritic cells (DC), play a significant role in the initiation of the immune response, presenting the virus antigens to T-cells, which contributes to the activation and differentiation of T-cells in various subpopulations of T-helpers (in particular, Th17), $\mathrm{CD}^{+}{ }^{+} \mathrm{T}$-cells, CD4 ${ }^{+} \mathrm{T}$-cells and NK-cell (Fig. 2). Notably, $\mathrm{CD} 8^{+} \mathrm{T}$-cells can provide a key cytotoxic function and reduce local infection with SARS-CoV-2, and $\mathrm{CD}^{+}{ }^{+} \mathrm{T}$-cells play a role in maintaining immune homeostasis in the intestine and other tissues and organs, and are also important in mediating humoral immunity [69]. T-helpers produce proinflammatory cytokines via the NF-kB signaling pathway. In particular, Th17 produces cytokines IL-1, IL-6, IL-8, IL-17, IL-21, TNF- $\beta$, and MCP-1, which attract lymphocytes and leukocytes from the intestinal mucosa to the site of infection [22]. Following virus infection, Th1 produces a number of high-level cytokines, including IL-2, IL-7, IL-6, G-CSF, IP-10, MCP-1, MIP-1A and TNF- $\alpha$, which, ultimately leads to the development of a "cytokine storm" [29]. The storm can reduce the viral load of SARS-CoV-2, but it can also lead to viral sepsis, multi organ damage caused by inflammation and complications of COVID-19, including patients with IBD. Th1 and Th17 cells are known to secrete proinflammatory cytokines IL-17, IFN- $\gamma$ and TNF, which contribute to inflammation in IBD by stimulating the production of TNF, IL-1, IL-6, IL-8, IL-12 and IL-18 by macrophages, endothelial cells and monocytes [70]. At the same time, during the exacerbation phase of UC there is an expression of IL-1, IL-6, IL- 8 and TNF- $\alpha$ at a high level, and the excessive Th1 and Th17 response to IL-12, IL-18 and IL-23 is a trigger for the development of $\mathrm{CD}$. According to this chain of events, the "cytokine storm" may have a negative impact on the course of IBD in patients with COVID-19 due to an uncontrolled increase in inflammation and progression of IBD.

The release of mediators, cytokines and chemokines by infected cells results in local accumulation of neutrophils, which can exert important antiviral effector functions and, in turn, secrete cytokines and chemokines that attract IELs (Fig. 2) [71]. Importantly, intestinal mucosal effector T-cells in IBD patients may be resistant or less responsive to Regulatory T-cells (Tregs) mediated inhibition. In turn, the production of IL-10 by Treg cells may be required to prevent intestinal inflammation [72]. The intracellular signaling pathways associated with components of innate immunity can induce the expression of co-stimulatory molecules CD40, CD80, and CD86 on antigen-presenting cells, which are necessary for the initiation of an adaptive immune response [63].

Based to the above, it can be concluded that the molecular pathways of the components of innate and adaptive immunity during infection with SARS-CoV-2 in patients with IBD, as well as the mechanisms of interaction and intersection of the signaling pathways of IBD, SARS-CoV-2 and components of innate and adaptive immunity have been studied insufficiently to draw unambiguous conclusions. More studies with a large number of participants are required to understand the precise molecular pathways and consequences of SARS-CoV-2 infection in IBD patients.

\section{Impact of SARS-COV-2 infection on the management of IBD}

Patients with IBD are reported to be at no greater risk of being infected with SARS-CoV-2 compared to patients without IBD [73, 74]. However, it is noted that these data cannot be interpreted unambiguously, since the absence of an increased risk of SARS-CoV-2 infection in those patients may be a result of patient compliance with measures of protection against SARS-CoV-2 infection: hygiene and social distancing. In turn, the reduction (or postponement) of endoscopic procedures and surgical interventions could also 
have a positive effect on the absence of an increased risk of infection with SARS-CoV-2 [75]. But it is important to understand that the reduction/postponement of these procedures, as well as the use of invasive surgical methods, can adversely affect the condition of a patient with IBD, lead to infection with SARS-CoV-2 or even death; in addition, carrying out emergency procedures/operations on SARS$\mathrm{CoV}-2$ infected patients with IBD can spread the infection to medical personnel. Therefore, today the implementation of routine procedures/operations for patients with IBD in the era of COVID-19 is significantly complicated and requires compliance with precautionary measures: the use of mandatory personal protection of medical personnel and the patient, disinfection of premises and equipment for carrying out procedures/operations, as well as, in particular, application of minimally invasive surgery (MIS), which has shown the greatest safety $[73,76]$. Given the possible oralfecal transmission of SARS-CoV-2 [45], additional precautions must be taken for trans-anal surgery: preoperative fecal analysis for SARS-CoV-2, surgery in operating rooms with negative pressure as preventing the escape of air from the operating room reduces the spread of SARS-CoV-2 [77].

According to The International Organization for the Study of Inflammatory Bowel Diseases (IOIBD), there are several scenarios for managing a patient with IBD: firstly, self-admitted patients with mild IBD with asymptomatic and mild SARS-CoV-2 infection, and secondly, self-visiting hospital patients with moderate to severe IBD with asymptomatic and mild SARS-CoV-2 infection; thirdly, hospitalized patients with severe COVID-19 and various forms of IBD (calm, moderate and severe) [78]. Each scenario assumes a different type of therapy, depending on the severity and characteristics of the course of both IBD and COVID-19 diseases, with the following drugs: 5-Aminosalicylic acid (5-ASA), oral budesonide, steroids, thiopurines, methotrexate, JAK inhibitor, anti-TNF therapy, anti-IL12/23 and antiintegrin. The possible interconnections between the listed IBD drugs and SARS-CoV-2 infection are discussed below.

\section{The relationship between IBD drug therapy and SARS-CoV-2 infection}

The safety of IBD drugs in the COVID-19 era remains an important area of research today [73]. Systemic use of corticosteroids in elderly patients with IBD and other comorbid conditions has been reported to be a risk factor for severe COVID-19 [79]. It is noted that the negative effect of corticosteroids depends on the stage of the disease. It is known that corticosteroids can reduce the expression of proinflammatory cytokines (IL-1, IL-2, IL- 6 , TNF- $\alpha$, IFN- $\gamma$ ) and thus blunt the hyperimmune response in critically ill IBD patients. However, at the same time, corticosteroids can suppress immune response, leading to impaired viral clearance in SARS-CoV-2 infected IBD patients [80, 81].

TNF antagonists are known to be the most commonly prescribed biological therapy for patients with IBD. However, it was shown that in case of combination therapy with TNF antagonists (a combination of thiopurines with TNF antagonists), as well as therapy with 5-ASA/sulfasalazine, a high severity of COVID-19 was observed in patients with IBD compared with monotherapy with TNF antagonists [82]. As suggested by the authors of this study, such a negative effect of combination TNF therapy on the severity of COVID-19 is determined by thiopurines. As previously reported, patients with IBD taking thiopurines developed lymphopenia. More so, patients with SARS-CoV-2 lymphopenia have a poorer prognosis and an increased risk of virus-related death [78]. As a result, it was proposed to cancel thiopurines during COVID-19 in elderly patients with IBD and other concomitant diseases, and use monotherapy with TNF antagonists instead, since it is not associated with a severe form of COVID-19. It is also suggested that anti-TNF therapy could be used to treat cytokine release syndrome in some patients characterized by high levels of proinflammatory cytokines such as IL-6 [78, 80]. However, this issue requires further study.

To date, there are no unambiguous data regarding the effect of methotrexate on COVID-19. However, the established pulmonary toxicity of methotrexate may increase the risk of infection/complication with SARS-CoV-2 [83].

Among the JAK inhibitors, Tofacitinib is used for the treatment of IBD, which can inhibit IFN- $\gamma$ activity, reduce the viral-mediated pro-inflammatory response, and block pro-inflammatory cytokines involved in the "cytokine storm" [80, 84]. In turn, another JAK inhibitor, Baricitinib, can suppress endocytosis. However, Baricitinib is in clinical trials for the treatment of IBD and has already shown promising results [85]. Presumably, the use of Baricitinib for the treatment of patients with IBD and COVID-19 could help to stop the possible penetration of SARS-CoV-2 via endosomal pathway. It is noted, that the ability to suppress endocytosis is not observed in the less selective JAK inhibitor Tofacitinib [80].

It has been shown that anti-integrin (vedolizumab) can inhibit $\alpha 4 \beta 7$-dependent homing of Th19 and Th9 cells, as well as regulatory T-cells into the mucous membrane of the gastrointestinal tract $[78,86]$. Until date, there is not enough information regarding the effect of vedolizumab on SARSCoV-2. However, the guidelines for the management of IBD patients in COVID-19 indicate the need to take into account the half-life of not only vedolizumab, but also other drugs $[73,83]$. This is important because the effects may persist even after the medication is stopped. For example, immunosuppressive therapy [anti-TNF, anti-IL12/23 (ustekinumab), anti-integrin (vedolizumab)] should be delayed by 2 weeks, 
because the immunosuppressive effects of these drugs will persist for several more weeks, which in turn is believed to cause severe COVID-19 [83]. In this case, anti-inflammatory non-immune therapy (5-ASA, oral budesonide, antibiotics) can be continued [82].

There are no studies on the effect of anti-IL12/23 (ustekinumab) therapy on patients with IBD and SARS-CoV-2 [71]. No increase in the number of cases of viral infections has been reported in patients with IBD taking ustekinumab [87]. However, it is assumed that blocking IL-23 in COVID19 can suppress the pathogenic Th17 response in a cytokine storm [71]. There are also no studies of oral budesonide in the context of possible interactions with COVID-19. Budesonide is being considered as an alternative to systemic corticosteroids [83, 88].

\section{Conclusions}

The analysis of studies of the signaling pathways of innate and adaptive immunity components during SARS-CoV-2 infection in IBD patients through a putative alternative route- the gastrointestinal tract, with the attachment of the virus to ACE2 expressed on IECs, allows identifying some molecular pathways and establishing possible mechanisms of immune response formation. In particular, intracellular and extracellular pathways for the existence of an immune response have been established by combining the result of infection with SARS-CoV-2 and the development and progression of IBD. Two intracellular molecular pathways for the transfer of genetic material into the host cell-endosomal and membrane (cytoplasmic) — have been considered, each leading to activation of the innate and adaptive immune responses, the formation of an inflammatory reaction, and an increase in the expression of pro-inflammatory cytokines. At the same time, a critical increase in the expression of cytokines can lead to a "cytokine storm", which can presumably affect the course of IBD in patients with COVID-19 through an uncontrolled enhancement of inflammation and progression of IBD.

The possible entry of SARS-CoV-2 RNA by pinocytosis through IECs with the recognition of viral RNA by TLR receptors, as well as the possible involvement of the RIG-I/ TLR3/NLRP3-dependent pathway, are highlighted. Unfortunately, no studies in the context of the relationship between RIG-I, SARS-CoV-2 and IBD are available. However, it can be assumed that the lack of activity of RIG-I protein and the penetration of SARS-CoV-2 through the IECs of the intestine by pinocytosis, will contribute to the development and progression of COVID-19 in patients with IBD, as well as concomitant intestinal inflammation.

Based on the available information, it is suggested that a cross talk between signaling pathways involved in SARS-CoV-2 infection and worsening of IBD state in response to subsequent expression of innate and adaptive immunity components is possible. In general, it can be assumed that any virus (including the new SARS-CoV-2), infecting intestinal tissues and/or entering the host's body through receptors located on intestinal IECs, may be a trigger for the onset of IBD in individuals with a genetic predisposition and/or the risk of developing IBD associated with other factors.

However, existing studies in the field of molecular interactions of IBD, components of innate and adaptive immunity, and SARS-CoV-2 are insufficient to unambiguously reveal the relationship between them and the ensuing consequences. The presently screened studies do not allow us to confirm or refute our hypotheses. As to date, according to the SECURE-IBD database (https://covidibd.org), the number of registered cases of COVID-19 in patients with IBD is more than 6000 . Of these, $42.24 \%$ are patients with UC and $57.76 \%$ are with CD. The number of IBD patients infected with SARS-CoV-2 is growing steadily every day. Based on the above, further research is needed to investigate the molecular pathways and consequences of SARS-CoV-2 infection in patients with IBD. The study of the exact molecular mechanisms and pathophysiology of SARS-CoV-2 is the basis for understanding the pathways of the initiation and development of COVID-19. The research on relationships between IBD drug therapy and SARS-CoV-2 will improve IBD treatment approaches and significantly reduce the potential risks of SARS-CoV-2 infection and/or complications from COVID-19.

Acknowledgements This work was supported by the Grant of the Government of the Russian Federation for the state support of scientific research carried out under the supervision of leading scientists, Agreement 14.W03.31.0009.

Author contributions KAD-conceptualized the project, screened the literature, designed and wrote the manuscript, prepared figures; EYB - conceptualized the project, edited, designed and wrote part of the manuscript; LPC - designed, revised and edited the manuscript; $\mathrm{AL}$ - designed, revised and edited the manuscript; all authors-read and approved the final manuscript.

\section{Declarations}

Conflict of interest There are no conflict of interests for all the authors.

\section{References}

1. Ng SC, Shi HY, Hamidi N, Underwood FE et al (2018) Worldwide incidence and prevalence of inflammatory bowel disease in the 21st century: a systematic review of population-based studies. Lancet 390(10114):2769-2778. https://doi.org/10.1016/S01406736(17)32448-0 
2. Costello SP, Soo W, Bryant RV et al (2017) Systematic review with meta-analysis: faecal microbiota transplantation for the induction of remission for active ulcerative colitis. Aliment Pharmacol Ther 46(3):213-224. https://doi.org/10.1111/apt.14173

3. Roda G, Chien Ng S, Kotze PG et al (2020) Crohn's disease. Nat Rev Dis Primers 6(22):1-19. https://doi.org/10.1038/ s41572-020-0156-2

4. Uhlig HH, Powrie F (2018) Translating immunology into therapeutic concepts for inflammatory bowel disease. Annu Rev Immunol 36:755-781. https://doi.org/10.1146/annurev-immun ol-042617-053055

5. Annese VA (2019) Review of extraintestinal manifestations and complications of inflammatory bowel disease. Saudi J Med Med Sci 7(2):66-73. https://doi.org/10.4103/sjmms.sjmms_81_18

6. Harbord M, Annese V, Vavricka SR, Allez M et al (2015) The first European evidence-based consensus on extra-intestinal manifestations in inflammatory bowel disease. J Crohns Colitis 10(3):239-254. https://doi.org/10.1093/ecco-jcc/jjv213

7. Ananthakrishnan AN, Bernstein CN, Iliopoulos D et al (2018) Environmental triggers in IBD: a review of progress and evidence. Nat Rev Gastroenterol Hepatol 15(1):39-49. https://doi.org/10. 1038/nrgastro.2017.136

8. Klenske E, Bojarski C, Waldner M, Rath T et al (2019) Targeting mucosal healing in Crohn's disease: what the clinician needs to know. Ther Adv Gastroenterol 12:1-11. https://doi.org/10.1177/ 1756284819856865

9. Feagan BG, Sandborn WJ, Gasink C et al (2016) Ustekinumab as induction and maintenance therapy for Crohn's disease. N Engl J Med 375(20):1946-1960. https://doi.org/10.1056/NEJMoa1602 773

10. Odenwald MA, Turner JR (2017) The intestinal epithelial barrier: a therapeutic target? Nat Rev Gastroenterol Hepatol 14:9-21. https://doi.org/10.1038/nrgastro.2016.169

11. Lerner A, Aminov R, Matthias T (2016) Dysbiosis may trigger autoimmune diseases via inappropriate posttranslational modification of host proteins. Front Microbiol 7:84. https://doi.org/10. 3389/fmicb.2016.00084

12. Vijay K (2018) Toll-like receptors in immunity and inflammatory diseases: past, present, and future. Int Immunopharmacol 59:391-412. https://doi.org/10.1016/j.intimp.2018.03.002

13. Lu Y, Li X, Liu S et al (2018) Toll-like receptors and inflammatory bowel disease. Front Immunol 9(72):1-9. https://doi.org/10. 3389/fimmu.2018.00072

14. de Souza HSP, Fiocchi C (2016) Immunopathogenesis of IBD: current state of the art. Nat Rev Gastroenterol Hepatol 13:13-27. https://doi.org/10.1038/nrgastro.2015.186

15. Khor B, Gardet A, Xavier RJ (2011) Genetics and pathogenesis of inflammatory bowel disease. Nature 474(7351):307-317. https:// doi.org/10.1038/nature10209

16. Liu JZ, van Sommeren S, Huang $\mathrm{H}$ et al (2015) Association analyses identify 38 susceptibility loci for inflammatory bowel disease and highlight shared genetic risk across populations. Nat Genet 47(9):979-986. https://doi.org/10.1038/ng.3359

17. Piovani D, Danese S, Peyrin-Biroulet L et al (2019) Environmental risk factors for inflammatory bowel diseases: an umbrella review of meta-analyses. Gastroenterology 157(3):647-659.e4. https://doi.org/10.1053/j.gastro.2019.04.016

18. Sartor RB, Wu GD (2017) Roles for intestinal bacteria, viruses, and fungi in pathogenesis of inflammatory bowel diseases and therapeutic approaches. Gastroenterology 152:327-339.e4. https:// doi.org/10.1053/j.gastro.2016.10.012

19. Lerner A (2020) Covid-19 and the human gut: a new runner on the tract. Int J Celiac Dis 8:64-67. https://doi.org/10.12691/ijcd-8-2-7

20. Burgueco JF, Reich A, Hazime H et al (2020) Expression of SARS-CoV-2 entry molecules ACE2 and TMPRSS2 in the gut of patients with IBD. Inflamm Bowel Dis 26(6):797-808. https:// doi.org/10.1093/ibd/izaa085

21. Cui J, Li F, Shi ZL (2018) Origin and evolution of pathogenic coronaviruses. Nat Rev Microbiol 17:181-192. https://doi.org/10. 1038/s41579-018-0118-9

22. Li G, Fan Y, Lai Y, Han T, Li Z, Zhou P et al (2020) Coronavirus infections and immune responses. J Med Virol 92(4):424-432. https://doi.org/10.1002/jmv.25685

23. Gralinski LE, Baric RS (2015) Molecular pathology of emerging coronavirus infections. J Pathol 235(2):185-195. https://doi.org/ 10.1002/path.4454

24. Wang K, Chen W, Zhou YS, Lian JQ et al (2020) SARS-CoV-2 invades host cells via a novel route: CD147-spike protein. bioRxiv. https://doi.org/10.1101/2020.03.14.988345

25. Shokri S, Mahmoudvand S, Taherkhani R, Farshadpour F (2019) Modulation of the immune response by middle east respiratory syndrome coronavirus. J Cell Physiol 234(3):2143-2151. https:// doi.org/10.1002/jcp.27155

26. Petrosillo N, Viceconte G, Ergonul O, Ippolito G, Petersen E (2020) COVID-19, SARS and MERS: are they closely related? Clin Microbiol Infect 26(6):729-734. https://doi.org/10.1016/j. cmi.2020.03.026

27. Lu R, Zhao X, Li J, Niu P et al (2020) Genomic characterisation and epidemiology of 2019 novel coronavirus: implications for virus origins and receptor binding. Lancet 395(10224):565-574. https://doi.org/10.1016/S0140-6736(20)30251-8

28. Zhou P, Yang XL, Wang XG et al (2020) A pneumonia outbreak associated with a new coronavirus of probable bat origin. Nature 579(7798):270-273. https://doi.org/10.1038/s41586-020-2012-7

29. Wu J, Yuan X, Wang B, Gu R, Li W, Xiang X, Tang L, Sun H (2020) Severe acute respiratory syndrome coronavirus 2: from gene structure to pathogenic mechanisms and potential therapy. Front Microbiol 11:1576. https://doi.org/10.3389/fmicb.2020. 01576

30. Kandeel M, Ibrahim A, Fayez M, Al-Nazawi M (2020) From SARS and MERS CoVs to SARS-CoV-2: moving toward more biased codon usage in viral structural and nonstructural genes. $\mathrm{J}$ Med Virol 92(6):660-666. https://doi.org/10.1002/jmv.25754

31. Chan JFW, Kok KH, Zhu Z, Chu H, To KKW, Yuan S, Yuen KY (2020) Genomic characterization of the 2019 novel humanpathogenic coronavirus isolated from a patient with atypical pneumonia after visiting Wuhan. Emerg Microbes Infect 9(1):221-236. https://doi.org/10.1080/22221751.2020.1719902

32. Khailany RA, Safdar M, Ozaslan M (2020) Genomic characterization of a novel SARS-CoV-2. Gene Rep 19:100682. https://doi. org/10.1016/j.genrep.2020.100682

33. Ehrenfeld M, Tincani A, Andreoli L, Cattalini M, Greenbaum A, Kanduc D et al (2020) Covid-19 and autoimmunity. Autoimmun Rev 19(8):102597. https://doi.org/10.1016/j.autrev.2020.102597

34. Zinserling VA, Vashukova MA, Vasilyeva MV, Isakov AN et al (2020) Issues of pathology of a new coronavirus infection COVID-19. Jurnal infectologii 12(2):5-11. https://doi.org/10. 22625/2072-6732-2020-12-2-5-11

35. Liu Y, Sawalha AH, Lu Q (2021) COVID-19 and autoimmune diseases. Curr Opin Rheumatol 33(2):155-162. https://doi.org/ 10.1097/BOR.0000000000000776

36. Kanduc D (2020) From anti-SARS-CoV-2 immune responses to COVID-19 via molecular mimicry. Antibodies 9(3):33. https:// doi.org/10.3390/antib9030033

37. Marino Gammazza A, Légaré S, Lo Bosco G et al (2020) Human molecular chaperones share with SARS-CoV-2 antigenic epitopes potentially capable of eliciting autoimmunity against endothelial cells: possible role of molecular mimicry in COVID-19. Cell Stress Chaperones 25:737-741. https://doi.org/10.1007/ s12192-020-01148-3 
38. Lucchese G, Flöel A (2020) SARS-CoV-2 and Guillain-Barré syndrome: molecular mimicry with human heat shock proteins as potential pathogenic mechanism. Cell Stress Chaperones 25(5):731-735. https://doi.org/10.1007/s12192-020-01145-6

39. Anand P, Puranik A, Aravamudan M, Venkatakrishnan AJ, Soundararajan V (2020) SARS-CoV-2 strategically mimics proteolytic activation of human ENaC. Elife 9:e58603. https://doi.org/10. 7554/eLife.58603

40. Halpert G, Shoenfeld Y (2020) SARS-CoV-2, the autoimmune virus. Autoimmun Rev 19(12):102695. https://doi.org/10.1016/j. autrev.2020.102695

41. Arango MT, Perricone C, Kivity S et al (2016) HLA-DRB1 the notorious gene in the mosaic of autoimmunity. Immunol Res 65(1):82-98. https://doi.org/10.1007/s12026-016-8817-7

42. Lorente L, Martín MM, Franco A et al (2021) HLA genetic polymorphisms and prognosis of patients with COVID-19. Polimorfismos genéticos de los HLA y pronóstico de pacientes con COVID19. Med Intensiva 45(2):96-103. https://doi.org/10.1016/j.medin. 2020.08.004

43. Tomita Y, Ikeda T, Sato R, Sakagami T (2020) Association between HLA gene polymorphisms and mortality of COVID-19: an in silico analysis. Immun Inflamm Dis 8(4):684-694. https:// doi.org/10.1002/iid3.358

44. Harmer D, Gilbert M, Borman R, Clark KL (2002) Quantitative mRNA expression profiling of ACE 2, a novel homologue of angiotensin converting enzyme. FEBS Lett 532:107-110. https:// doi.org/10.1016/s0014-5793(02)03640-2

45. Xiao F, Tang M, Zheng X, Liu Y, Li X, Shan H (2020) Evidence for gastrointestinal infection of SARS-CoV-2. Gastroenterology 158(6):1831-1833.e3. https://doi.org/10.1053/j.gastro.2020.02. 055

46. Zhang J, Wang S, Xue Y (2020) Fecal specimen diagnosis 2019 novel coronavirus-infected pneumonia. J Med Virol 92(6):680 682. https://doi.org/10.1002/jmv.25742

47. Chen L, Lou J, Bai Y, Wang M (2020) COVID-19 disease with positive fecal and negative pharyngeal and sputum viral tests. Am J Gastroenterol 115(5):790. https://doi.org/10.14309/ajg.00000 00000000610

48. Ma C, Cong Y, Zhang H (2020) COVID-19 and the digestive system. Am J Gastroenterol 115(7):1003-1006. https://doi.org/ 10.14309/ajg.0000000000000691

49. Zhang H, Kang Z, Gong $\mathrm{H}$ et al (2020) The digestive system is a potential route of 2019-nCov infection: a bioinformatics analysis based on single-cell transcriptomes. bioRxiv. https://doi.org/10. 1101/2020.01.30.927806

50. Liu Q, Wang RS, Qu GQ et al (2020) Gross observation report on autopsy of dead corpse system of covid-19. J Forensic Med 36(1):21-23. https://doi.org/10.12116/j.issn.1004-5619.2020.01. 005

51. Carvalho A, Alqusairi R, Adams A, Paul M, Kothari N, Peters S, DeBenedet AT (2020) SARS-CoV-2 gastrointestinal infection causing hemorrhagic colitis: implications for detection and transmission of COVID-19 disease. Am J Gastroenterol 115(6):942946. https://doi.org/10.14309/ajg.0000000000000667

52. Agarwal A, Chen A, Ravindran N, To C, Thuluvath PJ (2020) Gastrointestinal and liver manifestations of COVID-19. J Clin Exp Hepatol 10(3):263-265. https://doi.org/10.1016/j.jceh.2020. 03.001

53. Zhang C, Shi L, Wang FS (2020) Liver injury in COVID-19: management and challenges. Lancet Gastroenterol Hepatol 5(5):428430. https://doi.org/10.1016/S2468-1253(20)30057-1

54. Hashimoto T, Perlot T, Rehman A et al (2012) ACE2 links amino acid malnutrition to microbial ecology and intestinal inflammation. Nature 487(7408):477-481. https://doi.org/10.1038/natur e11228
55. Xu K, Cai H, Shen Y et al (2020) Management of corona virus disease-19 (COVID-19): the Zhejiang experience. Zhejiang Da Xue Xue Bao Yi Xue Ban 49(1):147-157. https://doi.org/10. 3785/j.issn.1008-9292.2020.02.02

56. Lin L, Lu L, Cao W, Li T (2020) Hypothesis for potential pathogenesis of SARS-CoV-2 infection-a review of immune changes in patients with viral pneumonia. Emerg Microbes Infect 9(1):727732. https://doi.org/10.1080/22221751.2020.1746199

57. Camilleri M (2019) Leaky gut: mechanisms, measurement and clinical implications in humans. Gut 68:1516-1526. https://doi. org/10.1136/gutjnl-2019-318427

58. Thachil E, Hugot JP, Arbeille B et al (2012) Abnormal activation of autophagy-induced crinophagy in Paneth cells from patients with Crohn's disease. Gastroenterology 142:1097-1099. https:// doi.org/10.1053/j.gastro.2012.01.031

59. Yang JY, Kim MS, Kim E et al (2016) Enteric viruses ameliorate gut inflammation via toll-like receptor 3 and toll-like receptor 7-mediated interferon- $\beta$ production. Immunity 44(4):889-900. https://doi.org/10.1016/j.immuni.2016.03.009

60. Choudhury A, Mukherjee S (2020) In silico studies on the comparative characterization of the interactions of SARS-CoV-2 spike glycoprotein with ACE-2 receptor homologs and human TLRs. J Med Virol. https://doi.org/10.1002/jmv.25987

61. Astuti I (2020) Severe Acute Respiratory Syndrome Coronavirus 2 (SARS-CoV-2): an overview of viral structure and host response. Diabetes Metab Syndr 14(4):407-412. https://doi.org/10.1016/j. dsx.2020.04.020

62. Deiteren A, De Man JG, Ruyssers NE, Moreels TG, Pelckmans PA, De Winter BY (2014) Histamine H4 and H1 receptors contribute to postinflammatory visceral hypersensitivity. Gut 63(12):1873-1882. https://doi.org/10.1136/gutjnl-2013-305870

63. Van den Berg DF, te Velde AA (2020) Severe COVID-19: NLRP3 inflammasome dysregulated. Front Immunol 11:1580. https://doi. org/10.3389/fimmu.2020.01580

64. Zhao C, Zhao W (2020) NLRP3 inflammasome-a key player in antiviral responses. Front Immunol 11:211. https://doi.org/10. 3389/fimmu.2020.00211

65. Cenac N, Altier C, Motta JP, d'Aldebert E, Galeano S, Zamponi GW, Vergnolle N (2010) Potentiation of TRPV4 signalling by histamine and serotonin: an important mechanism for visceral hypersensitivity. Gut 59(4):481-488. https://doi.org/10.1136/gut. 2009.192567

66. Chen IY, Moriyama M, Chang MF, Ichinohe T (2019) Severe acute respiratory syndrome coronavirus viroporin $3 \mathrm{a}$ activates the NLRP3 inflammasome. Front Microbiol 10:50. https://doi.org/10. 3389/fmicb.2019.00050

67. Zhen Y, Zhang H (2019) NLRP3 inflammasome and inflammatory bowel disease. Front Immunol 10:276. https://doi.org/10.3389/ fimmu.2019.00276

68. Yu M, Levine SJ (2011) Toll-like receptor, RIG-I-like receptors and the NLRP3 inflammasome: key modulators of innate immune responses to double-stranded RNA viruses. Cytokine Growth Factor Rev 22(2):63-72. https://doi.org/10.1016/j.cytogfr.2011.02. 001

69. Chen G, Wu D, Guo W et al (2020) Clinical and immunological features of severe and moderate coronavirus disease 2019. J Clin Invest 130(5):2620-2629. https://doi.org/10.1172/JCI137244

70. Pazmandi J, Kalinichenko A, Ardy RC, Boztug K (2019) Earlyonset inflammatory bowel disease as a model disease to identify key regulators of immune homeostasis mechanisms. Immunology 287:162-185. https://doi.org/10.1111/imr.12726

71. Neurath MF (2020) Covid-19 and immunomodulation in IBD. Gut 69(7):1335-1342. https://doi.org/10.1136/gutjnl-2020-321269

72. Zhu L, Shi T, Zhong C, Wang Y, Chang M, Liu X et al (2017) IL-10 and IL-10 receptor mutations in very early onset 
inflammatory bowel disease. Gastroenterol Res 10(2):65-69. https://doi.org/10.14740/gr740w

73. Chebli JMF, Queiroz NSF, Damião AOMC et al (2021) How to manage inflammatory bowel disease during the COVID-19 pandemic: a guide for the practicing clinician. World J Gastroenterol 27(11):1022-1042. https://doi.org/10.3748/wjg.v27.i11.1022

74. Aziz M, Fatima R, Haghbin H, Lee-Smith W, Nawras A (2020) The incidence and outcomes of COVID-19 in IBD patients: a rapid review and meta-analysis. Inflamm Bowel Dis 26(10):e132e133. https://doi.org/10.1093/ibd/izaa170

75. Søreide K, Hallet J, Matthews JB et al (2020) Immediate and longterm impact of the COVID-19 pandemic on delivery of surgical services. Br J Surg 107(10):1250-1261. https://doi.org/10.1002/ bjs. 11670

76. Somashekhar SP, Acharya R, Saklani A et al (2020) Adaptations and safety modifications to perform safe Minimal Access Surgery (MIS: Laparoscopy and Robotic) during the COVID-19 pandemic: practice modifications expert panel consensus guidelines from Academia of Minimal Access Surgical Oncology (AMASO). Indian J Surg Oncol 18:1-11. https://doi.org/10.1007/ s13193-020-01254-9

77. de Leeuw RA, Burger NB, Ceccaroni M et al (2020) COVID-19 and laparoscopic surgery: scoping review of current literature and local expertise. JMIR Public Health Surveill 6(2):e18928. https:// doi.org/10.2196/18928

78. Rubin DT, Abreu MT, Rai V, Siegel CA (2020) International Organization for the study of inflammatory bowel disease: management of patients with Crohn's disease and ulcerative colitis during the coronavirus disease-2019 pandemic: results of an International Meeting. Gastroenterology 159(1):6-13. https://doi.org/ 10.1053/j.gastro.2020.04.002

79. Brenner EJ, Ungaro RC, Gearry RB et al (2020) Corticosteroids, but not TNF antagonists, are associated with adverse COVID-19 outcomes in patients with inflammatory bowel diseases: results from an international registry. Gastroenterology 159(2):481-491. e3. https://doi.org/10.1053/j.gastro.2020.05.032

80. Sebastian S, Gonzalez HA, Peyrin-Biroulet L (2020) Safety of drugs during previous and current coronavirus pandemics: lessons for inflammatory bowel disease. J Crohns Colitis 14(11):16321643. https://doi.org/10.1093/ecco-jcc/jjaa120
81. Russell CD, Millar JE, Baillie JK (2020) Clinical evidence does not support corticosteroid treatment for 2019-nCoV lung injury. Lancet 395:473-475. https://doi.org/10.1016/S0140-6736(20) 30317-2

82. Ungaro RC, Brenner EJ, Gearry RB et al (2021) Effect of IBD medications on COVID-19 outcomes: results from an international registry. Gut 70(4):725-732. https://doi.org/10.1136/ gutjnl-2020-322539

83. Rubin DT, Feuerstein JD, Wang AY, Cohen RD (2020) AGA clinical practice update on management of inflammatory bowel disease during the COVID-19 pandemic: expert commentary. Gastroenterology 159(1):350-357. https://doi.org/10.1053/j.gastro.2020. 04.012

84. Jamilloux Y, El Jammal T, Vuitton L et al (2019) JAK inhibitors for the treatment of autoimmune and inflammatory diseases. Autoimmun Rev 18(11):102390. https://doi.org/10.1016/j.autrev. 2019.102390

85. Richardson P, Griffin I, Tucker C et al (2020) Baricitinib as potential treatment for 2019-nCoV acute respiratory disease. Lancet 395(10241):e30-e31. https://doi.org/10.1016/S0140-6736(20) 30304-4

86. Ng SC, Hilmi IN, Blake A et al (2018) Low frequency of opportunistic infections in patients receiving vedolizumab in clinical trials and post-marketing setting. Inflamm Bowel Dis 24(11):24312441. https://doi.org/10.1093/ibd/izy153

87. Ghosh S, Gensler LS, Yang Z et al (2019) Ustekinumab safety in psoriasis, psoriatic arthritis, and Crohn's disease: an integrated analysis of phase II/III clinical development programs. Drug Saf 42(6):751-768. https://doi.org/10.1007/s40264-019-00797-3

88. Lichtenstein GR, Rubin DT (2020) Coronavirus and patients with inflammatory bowel disease: management strategies for the practicing clinician. Am J Gastroenterol 115(10):1566-1569. https:// doi.org/10.14309/ajg.0000000000000817

Publisher's Note Springer Nature remains neutral with regard to jurisdictional claims in published maps and institutional affiliations. 